\title{
BMJ Global Health Determinants of neonatal, infant and under-five mortality in a war-affected country: analysis of the 2010 Household Health Survey in South Sudan
}

\author{
Ngatho Samuel Mugo, ${ }^{1}$ Kingsley E Agho, ${ }^{2}$ Anthony B Zwi, ${ }^{3}$ Eliaba Yona Damundu, ${ }^{4}$ \\ Michael J Dibley ${ }^{1}$
}

To cite: Mugo NS, Agho KE, Zwi $\mathrm{AB}$, et al. Determinants of neonatal, infant and under-five mortality in a war-affected country: analysis of the 2010 Household Health Survey in South Sudan. BMJ Glob Health 2018;3:e000510. doi:10.1136/ bmjgh-2017-000510

\section{Handling editor Sanni Yaya}

- Additional material is published online only. To view please visit the journal online (http://dx.doi.org/10.1136/ bmjgh-2017-000510).

Received 3 August 2017 Revised 4 December 2017 Accepted 13 December 2017

Check for updates

${ }^{1}$ School of Public Health, University of Sydney, Sydney, New South Wales, Australia ${ }^{2}$ School of Science and Health, Western Sydney University, Penrith, New South Wales, Australia

${ }^{3}$ School of Social Sciences, University of New South Wales, Sydney, New South Wales, Australia

${ }^{4}$ UNICEF South Sudan, Toto Chan Compound, Juba, South Sudan

Correspondence to Ngatho Samuel Mugo; n.mugo@hotmail.com

\section{ABSTRACT}

Background Under-five children born in a fragile and war-affected setting of South Sudan are faced with a high risk of death as reflecting in high under-five mortality. In South Sudan health inequities and inequitable condition of daily living play a significant role in childhood mortality. This study examines factors associated with under-five mortality in South Sudan.

Methods The study population includes 8125 singleton, live birth, under-five children born in South Sudan within 5 years prior to the 2010 South Sudan Household Survey. Factors associated with neonatal, infant and under-five deaths were examined using generalised linear latent and mixed models with the logit link and binomial family that adjusted for cluster and survey weights.

Results The multivariate analysis showed that mothers who reported a previous death of a child reported significantly higher risk of neonatal (adjusted OR $(\mathrm{AOR})=3.74,95 \%$ confidence interval $(\mathrm{Cl} 2.88$ to 4.87$)$, $\mathrm{P}<0.001)$, infant $(\mathrm{AOR}=3.19,95 \% \mathrm{Cl}(2.62$ to 3.88$)$, $\mathrm{P}<0.001)$ and under-five deaths $(\mathrm{AOR}=3.07,95 \% \mathrm{Cl}(2.58$ to 3.64), $P<0.001)$. Other associated factors included urban dwellers ( $A 0 R=1.37,95 \% \mathrm{Cl}(1.01$ to 1.87$), \mathrm{P}=0.045)$ for neonatal, $(A O R=1.35,95 \% \mathrm{Cl}$ (1.08 to 1.69), $\mathrm{P}=0.009)$ for infants and $(A O R=1.39,95 \% \mathrm{Cl}$ (1.13 to 1.71), $\mathrm{P}=0.002)$ for under-five death. Unimproved sources of drinking water were significantly associated with neonatal mortality ( $A 0 \mathrm{R}=1.91,95 \% \mathrm{Cl}$ (1.11 to 3.31), $\mathrm{P}=0.02$ ).

Conclusions This study suggested that the condition and circumstances in which the child is born into, and lives with, play a role in under-five mortality, such as higher mortality among children born to teenage mothers. Ensuring equitable healthcare service delivery to all disadvantaged populations of children in both urban and rural areas is essential but remains a challenge, while violence continues in South Sudan.

\section{BACKGROUND}

Reduction of the under-five mortality rate of 25 or fewer deaths per 1000 live births by 2030 is one of the priorities of the Sustainable Development Goals and the target for the child survival indicator specially in a country like South Sudan. ${ }^{1}$ Over the past 25 years

\section{Key messages}

What is already known about this topic?

- Children born in a fragile and war-affected setting of South Sudan are at increased risk of a high rate of neonatal, infant and under-five mortality.

What are the new findings?

- In South Sudan, exposure to indoor air pollution and use of unimproved source of drinking water were associated with increased risk of neonatal mortality.

- Children born in urban areas of South Sudan were at greater risk of death than other children born in rural areas.

Recommendations for policy

- Implementing and enabling policy environment and reforms to alleviate poor living conditions of the household is essential.

- Improving services in population subgroups, which might not usually be the focus of child survival programmes, for example, among returnees, and internally displaced persons in urban populations is essential.

progress has been made globally in reducing under-five mortality rate by $51 \%$, from 91 deaths per 1000 live births in 1990 to 43 in $2015 .^{2}$ However, the global decline of underfive mortality fell short of the two-thirds reduction envisaged in the Millennium Development Goals era. ${ }^{3}$ Many low-income countries in Sub-Saharan Africa and South Asia continue to face high rates of under-five mortality estimated at 83 and 51 per 1000 live births in 2015 , respectively. ${ }^{34}$

In many countries affected by war, the risk of under-five mortality was found to be 80 times higher than those countries not affected by war. ${ }^{45}$ According to World Bank estimates, of the 20 countries with the highest under-five mortality rate in the world, nine were from war-torn countries including South Sudan. ${ }^{4}$ 


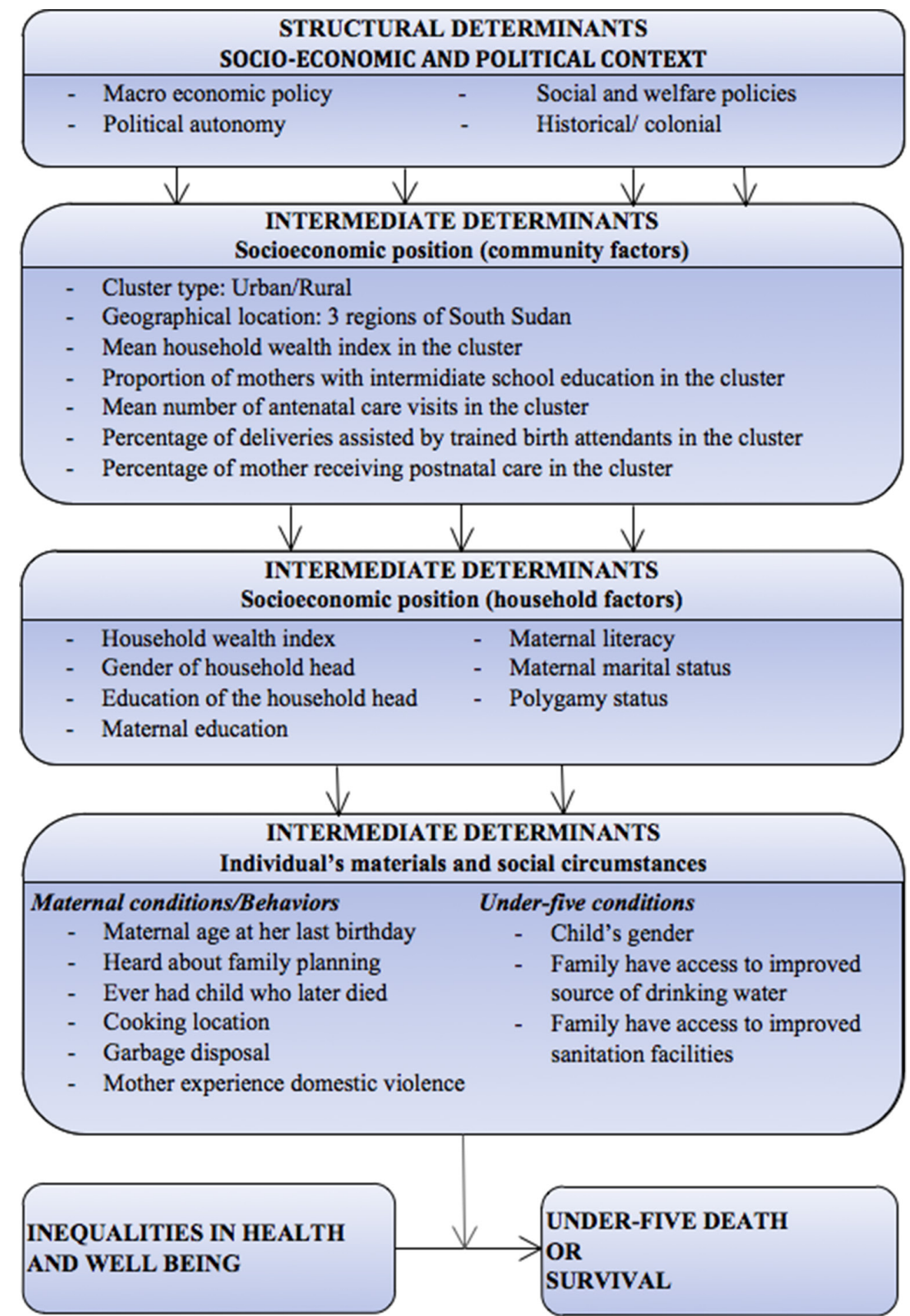

Figure 1 Conceptual framework for factors associated with under-five mortality, adapted from the WHO social determinants of health inequalities.

The rate of under-five mortality per 1000 births in these countries was between 139 per 1000 births in Chad and 93 per 1000 births in South Sudan. ${ }^{6}$

South Sudan is the world's youngest country that is still affected by war after gaining independence in 2011. ${ }^{7}$ The war has severely affected the country's socioeconomic development and has claimed over 2 million of lives since $1956 .^{8}$ In South Sudan, it is estimated that about $75 \%$ of the population has no access to healthcare services, $63 \%$ of adult population is illiterate and over $50 \%$ of the population is living on less than US $\$ 1$ per day. ${ }^{9}$ Children from low socioeconomic households are at increased risk of premature death and disability due to low access to essential lifesaving interventions than those children with access to established public health interventions. ${ }^{1011}$ On average, about $50 \%$ of under-five children in South Sudan have no access to evidencebased interventions, such as access to insecticide-treated mosquito nets $(34 \%)$, improved sources of drinking water $(69 \%)$, improved sanitation facilities $(7 \%)$, rehydration treatment for diarrhoea (49\%), antibiotic treatment for pneumonia $(33 \%)$ and childhood immunisations $(6 \%) .^{12}$ Therefore, in South Sudan health inequities and inequitable condition of daily living can be explained by poor social policies, unfair economic arrangements and bad politics. ${ }^{13}$ 
In order to address the social determinates of health inequality that are preventable, avoidable and unfair, the WHO established in 2005 the Commission on Social Determinants of Health as a global strategic mechanism to address the problems associated with health equity. ${ }^{14}$ According to the WHO model, the chance of dying in childhood is strongly determined by the living conditions into which the child is born and the systems in place to deal with illness. ${ }^{1415}$ For example, the probability of dying in childhood is strongly related to remoteness, rural dwelling and the socioeconomic position of the parents or household. ${ }^{1617}$ These factors are further shaped by the socioeconomic and political mechanisms, such as macroeconomic policy. Therefore, social and economic policies have a determining impact on whether a child can develop to her/his full potential and live and flourish or whether her/his life will be withered. ${ }^{15}$

Past studies from the postconflict settings indicate that children are particularly vulnerable to the consequences of violence, poverty, being a child solider, landmine injuries and mental health impairment, ${ }^{18-20}$ which might increase their risk of mortality. Therefore, examining under-five mortality in the postconflict setting of South Sudan is a valid indicator for monitoring child health and survival, and for developing programmes aimed at improving access to evidence-based interventions for child health. This study aims to identify factors associated with neonatal, infant and under-five mortality in South Sudan. Findings from this study will enable policymakers and public health practitioners to develop cost-effective lifesaving interventions targeting the subpopulation of children at risk.

\section{METHODS}

\section{Data sources}

We used a data set collected during the 2010 South Sudan Household Health Survey second round (SSHHSII), which is a nationally representative, stratified, cluster sample survey, covering the 10 states of South Sudan. The survey was largely based on the Unicef's Multiple Indicator Cluster Survey (MICS) methodology. ${ }^{21}$ It aimed to collect health and related indicators essential for identifying the health needs of women and children, and for establishing priorities for evidence-based planning, decision-making and reporting. The SSHHSII comprised a general questionnaire to collect basic demographic information on all household members, with three individual questionnaires addressed to specific target groups: women and men aged 15-49 years and underfive children. The individual questionnaire was used to collect information on reproductive history, use of family planning, information about child health indicators and other health-related issues. The questionnaire for underfive children was administered to mothers or caretakers of children under 5 years of age. ${ }^{21}$

A two-stage cluster sampling design was employed for the selection of the sample in each of the 10 states of
South Sudan. The first stage consisted of the selection of the required number of enumeration areas separately by urban and rural strata. Systematic probability proportional to size sampling procedure was used for the selection of 40 enumeration sites in each of the 10 states of South Sudan. The second stage was the selection of the total number of households in each cluster using random systematic selection procedures to select on average 25 households in each enumeration area. From the selected households, a total sample of 9369 households were interviewed with information from 9069 ever-married women, and 4344 men aged 15-49 years, and information from 8338 under-five children collected from their mother/ caretaker yielding a response rate of $83 \%$. The details of the SSHHSII sampling method have been reported elsewhere. $^{21}$

\section{Study population}

Our study population consisted of 9125 (8125 weighted) singleton live-born children under the age of 5 years, who were born within 5 years prior to the survey. We excluded multiple pregnancies $(n=303)$ in this analysis because of higher risk of newborn death, as the result of preterm birth and pregnancy complications among this group compared with singleton pregnancies. ${ }^{22}$

\section{Conceptual framework}

We modified and used the conceptual framework developed by $\mathrm{WHO}^{14}$ as a guide in identifying the key social determinants of health inequalities and their impact on the well-being of under-five children in this study. According to this framework, a set of the social economic positions, such as education, income, occupation, gender and social class, is shaped by the structural social, economic and political context. ${ }^{14}$ Furthermore, these socioeconomic positions influence an individual's health and well-being through more specific factors called intermediate factors such as material circumstances, behaviours, biological factors and health services. According to the framework, we identified 26 possible determinants and predictors of under-five mortality in South Sudan based on the available information from the 2010 SSHHSII data sets. Figure 1 presents the modified conceptual framework used in this analysis.

\section{Study variables}

The outcome variable for this analysis was neonatal, infant and under-five mortality expressed in a binary form ( 0 for living child and 1 for a child death). Neonatal mortality is defined as the probability of dying in the first month of life ( 0 to 28 days), infant mortality is the probability of dying between birth and first birthday ( 0 to $<12$ months) and under-five mortality is the death of a child under the age of 5 years ( 0 to $<60$ months). We obtained information on under-five deaths collected from the birth history section of the questionnaire administered to individual female respondents aged $15-49$ years, who had ever given birth during the 5 -year period prior to 
Table 1 The prevalence of the study variables and the under-five mortality rate according to socioeconomic and intermediate factors, South Sudan Household Survey, 2010 ( $n=8215)$

\begin{tabular}{|c|c|c|c|c|c|}
\hline \multirow[b]{2}{*}{ Variables } & \multicolumn{2}{|c|}{ Number (percentage) } & \multicolumn{3}{|c|}{ Mortality rate* } \\
\hline & $\mathbf{N}$ & n (\%) $)^{*}$ & Neonatal & Infant & Under-five \\
\hline \multicolumn{6}{|l|}{ Intermediate determinants } \\
\hline \multicolumn{6}{|l|}{ Socioeconomic position } \\
\hline \multicolumn{6}{|l|}{ Community factors } \\
\hline \multicolumn{6}{|l|}{ Type of cluster } \\
\hline Rural & 7146 & $6134(74.7)$ & 37 & 69 & 95 \\
\hline Urban & 2630 & $2081(25.3)$ & 50 & 90 & 120 \\
\hline \multicolumn{6}{|l|}{ Geographical regions } \\
\hline Greater Upper Nile & 2840 & 2639 (32.1) & 38 & 70 & 96 \\
\hline Greater Bahr el Ghazal & 3838 & 2733 (33.3) & 37 & 74 & 98 \\
\hline Greater Equatoria & 3098 & $2843(34.6)$ & 46 & 78 & 109 \\
\hline \multicolumn{6}{|l|}{ Household factors } \\
\hline \multicolumn{6}{|l|}{ Household wealth index } \\
\hline Wealthier & 2708 & 2734 (33.3) & 43 & 74 & 101 \\
\hline Middle & 2737 & 2741 (33.4) & 38 & 72 & 99 \\
\hline Poor & 2794 & 2740 (33.4) & 41 & 77 & 103 \\
\hline \multicolumn{6}{|l|}{ Gender of household head } \\
\hline Male & 5405 & $4472(57.1)$ & 40 & 73 & 100 \\
\hline Female & 3930 & $3364(42.9)$ & 40 & 74 & 103 \\
\hline \multicolumn{6}{|l|}{ Education of the household head } \\
\hline Secondary+ education & 766 & $628(8.0)$ & 49 & 70 & 95 \\
\hline No education/primary education & 8569 & 7209 (92.0) & 39 & 74 & 102 \\
\hline \multicolumn{6}{|l|}{ Maternal education } \\
\hline Intermediate+ education & 310 & $322(3.9)$ & 29 & 68 & 86 \\
\hline Primary/informal adult education & 1277 & $1286(15.7)$ & 30 & 69 & 93 \\
\hline No education & 6638 & $6597(80.4)$ & 42 & 73 & 100 \\
\hline \multicolumn{6}{|l|}{ Maternal literacy } \\
\hline Able to read & 794 & $823(10.4)$ & 35 & 58 & 84 \\
\hline Unable to read & 7155 & $7096(89.6)$ & 40 & 75 & 105 \\
\hline \multicolumn{6}{|l|}{ Maternal marital status } \\
\hline Never married (single) & 1155 & $1123(13.7)$ & 36 & 61 & 89 \\
\hline Formerly married & 1220 & $1256(15.3)$ & 42 & 75 & 93 \\
\hline Currently married & 5864 & $5835(71.0)$ & 41 & 76 & 105 \\
\hline \multicolumn{6}{|l|}{ Polygamy status } \\
\hline Husband has one wife. & 3890 & $3950(57.3)$ & 39 & 76 & 103 \\
\hline Husband has more than one wife & 2978 & $2947(42.7)$ & 42 & 76 & 104 \\
\hline
\end{tabular}

Individual's circumstances

\begin{tabular}{|c|c|c|c|c|c|}
\hline \multicolumn{6}{|c|}{ Maternal conditions/behaviours } \\
\hline \multicolumn{6}{|c|}{ Maternal age at her last birthday (years) } \\
\hline 20-34 & 5251 & $5206(63.4)$ & 37 & 70 & 96 \\
\hline $15-19$ & 901 & $873(10.6)$ & 46 & 84 & 111 \\
\hline $35-49$ & 2087 & $2136(26.0)$ & 47 & 80 & 109 \\
\hline \multicolumn{6}{|c|}{ Heard about family planning } \\
\hline No & 6738 & $6630(81.0)$ & 38 & 70 & 96 \\
\hline
\end{tabular}


Table 1 Continued

\begin{tabular}{|c|c|c|c|c|c|}
\hline \multirow[b]{2}{*}{ Variables } & \multicolumn{2}{|c|}{ Number (percentage) } & \multicolumn{3}{|c|}{ Mortality rate* } \\
\hline & $\mathbf{N}$ & $\mathrm{n}(\%)^{*}$ & Neonatal & Infant & Under-five \\
\hline Yes & 1476 & $1557(19.0)$ & 51 & 90 & 121 \\
\hline \multicolumn{6}{|l|}{ Ever had child who later died } \\
\hline No & 5175 & $5210(72.3)$ & 23 & 48 & 69 \\
\hline Yes & 2019 & $1994(27.7)$ & 83 & 140 & 180 \\
\hline \multicolumn{6}{|l|}{ Cooking location } \\
\hline Kitchen & 2696 & $2245(29.2)$ & 45 & 78 & 109 \\
\hline Elsewhere in the house & 1868 & $1556(20.2)$ & 41 & 71 & 91 \\
\hline Outdoors & 4592 & $3896(50.6)$ & 37 & 72 & 91 \\
\hline \multicolumn{6}{|l|}{ Garbage disposal } \\
\hline Burning & 3580 & $3019(39.0)$ & 40 & 76 & 101 \\
\hline Dumping (throwing outside the house) & 5655 & $4732(61.1)$ & 39 & 72 & 102 \\
\hline \multicolumn{6}{|l|}{ Mother experienced domestic violence in the past year } \\
\hline No & 6138 & $6072(77.1)$ & 41 & 76 & 101 \\
\hline Yes & 1748 & $1808(22.9)$ & 40 & 71 & 102 \\
\hline \multicolumn{6}{|l|}{ Under-five condition } \\
\hline \multicolumn{6}{|l|}{ Under-five gender } \\
\hline Female & 4839 & $4057(49.4)$ & 40 & 76 & 97 \\
\hline Male & 4937 & $4158(50.6)$ & 41 & 72 & 105 \\
\hline \multicolumn{6}{|c|}{ Family have access to improved source of drinking water } \\
\hline Yes & 970 & $807(10.4)$ & 24 & 58 & 88 \\
\hline No & 8244 & 6927 (89.6) & 42 & 75 & 102 \\
\hline \multicolumn{6}{|l|}{ Family have access to improved sanitation facilities } \\
\hline Yes & 1068 & $877(11.2)$ & 37 & 68 & 98 \\
\hline No & 8255 & $6949(88.8)$ & 40 & 74 & 101 \\
\hline \multicolumn{6}{|l|}{ Community-level factors } \\
\hline $\begin{array}{l}\text { Mean household wealth index in the } \\
\text { cluster, mean (SD) }\end{array}$ & NA & $2.22(0.36)$ & NA & NA & NA \\
\hline $\begin{array}{l}\text { Proportion of mothers who attended } \\
\text { intermediate education in the cluster, mean (SD) }\end{array}$ & NA & $0.04(0.09)$ & NA & NA & NA \\
\hline $\begin{array}{l}\text { Mean number of antenatal care visits in the } \\
\text { cluster, mean (SD) }\end{array}$ & NA & $2.73(0.28)$ & NA & NA & NA \\
\hline $\begin{array}{l}\text { Percentage of deliveries assisted by trained birth } \\
\text { attendants in the cluster, mean (SD) }\end{array}$ & NA & $0.19(0.17)$ & NA & NA & NA \\
\hline $\begin{array}{l}\text { Percentage of mothers receiving postnatal care } \\
\text { in the cluster, mean (SD) }\end{array}$ & NA & $0.09(0.12)$ & NA & NA & NA \\
\hline
\end{tabular}

*Weighted for the sampling probability.

NA, not applicable.

the survey. The under-five mortality rate was estimated directly from the information on the birth history using the child's date of birth, date of interview and age at death. We calculated the mortality rate for this analysis as the number of children dying during each age period (neonatal, infant and under-five) per 1000 live births in a given year.

The independent variables for this analysis were categorised based on the WHO conceptual framework. At the socioeconomic position, 14 distal factors were identified and classified as follows: (1) community factors consisting of cluster type and region (representing the characteristics of a cluster); the mean household wealth index (representing economic status); the proportion of mothers with at least intermediate education (representing maternal factors); and the mean number of antenatal care visits, percentage of mothers receiving postnatal care and the percentage of deliveries assisted by skilled birth attendants in the cluster (representing community access to maternal health services); and (2) household factors 
Table 2 Adjusted and unadjusted ORs for factors associated with neonatal mortality according to socioeconomic and intermediate factors, analysis of South Sudan Household Survey, 2010 ( $n=8215)$

\begin{tabular}{lllllll}
\hline Variables & OR $^{*}$ & $95 \% \mathrm{Cl} \dagger$ & P value & AOR & $95 \% \mathrm{Cl}$ & $\mathbf{P}$ value
\end{tabular}

\section{Intermediate determinants}

Socioeconomic position

Community factors

Type of cluster

\begin{tabular}{|c|c|c|c|c|c|c|}
\hline Rural & 1.00 & & & 1.00 & & \\
\hline Urban & 1.37 & (1.01 to 1.87$)$ & 0.045 & 1.37 & (1.01 to 1.87$)$ & 0.045 \\
\hline \multicolumn{7}{|l|}{ Geographical location (regions) } \\
\hline Greater Upper Nile & 1.00 & & & & & \\
\hline Greater Bahr el Ghazal & 1.00 & (0.70 to 1.14$)$ & 0.984 & & & \\
\hline Greater Equatoria & 1.24 & $(0.88$ to 1.74$)$ & 0.223 & & & \\
\hline Mean household wealth index in the cluster & 0.86 & (0.60 to 1.23$)$ & 0.418 & & & \\
\hline $\begin{array}{l}\text { Proportion of mothers with intermediate school } \\
\text { education in the cluster }\end{array}$ & 1.52 & $(0.36$ to 6.54$)$ & 0.571 & & & \\
\hline $\begin{array}{l}\text { Mean number of antenatal care visits in the } \\
\text { cluster }\end{array}$ & 0.84 & (0.01 to 1.34$)$ & 0.493 & & & \\
\hline $\begin{array}{l}\text { Percentage of deliveries assisted by trained birth } \\
\text { attendants in the cluster }\end{array}$ & 0.91 & (0.40 to 2.06$)$ & 0.812 & & & \\
\hline $\begin{array}{l}\text { Percentage of mothers receiving postnatal care } \\
\text { in the cluster }\end{array}$ & 1.26 & (0.37 to 4.22$)$ & 0.713 & & & \\
\hline \multicolumn{7}{|l|}{ Household factors } \\
\hline \multicolumn{7}{|l|}{ Household wealth index } \\
\hline Wealthier & 1.00 & & & & & \\
\hline Middle & 0.97 & (0.74 to 1.29$)$ & 0.856 & & & \\
\hline Poor & 0.97 & (0.74 to 1.28$)$ & 0.844 & & & \\
\hline \multicolumn{7}{|l|}{ Gender of household head } \\
\hline Male & 1.00 & & & & & \\
\hline Female & 0.99 & (0.78 to 1.25$)$ & 0.931 & & & \\
\hline \multicolumn{7}{|l|}{ Education of the household head } \\
\hline Secondary+ education & 1.00 & & & & & \\
\hline No education/primary education & 0.81 & $(0.55$ to 1.20$)$ & 0.292 & & & \\
\hline \multicolumn{7}{|l|}{ Maternal education } \\
\hline Intermediate+ education & 1.00 & & & & & \\
\hline Primary education & 0.71 & (0.39 to 1.29$)$ & 0.260 & & & \\
\hline No education & 0.83 & (0.48 to 1.44$)$ & 0.517 & & & \\
\hline \multicolumn{7}{|l|}{ Maternal literacy } \\
\hline Able to read & 1.00 & & & & & \\
\hline Unable to read & 1.28 & (0.85 to 1.92$)$ & 0.245 & & & \\
\hline \multicolumn{7}{|l|}{ Maternal marital status } \\
\hline Never married (single) & 1.00 & & & & & \\
\hline Formerly married & 1.13 & $(0.73$ to 1.73$)$ & 0.588 & & & \\
\hline Currently married & 1.1 & (0.78 to 1.56$)$ & 0.587 & & & \\
\hline \multicolumn{7}{|l|}{ Polygamy status } \\
\hline Husband had one wife & 1.00 & & & & & \\
\hline Husband had more than one wife & 1.04 & (0.81 to 1.34$)$ & 0.736 & & & \\
\hline
\end{tabular}




\begin{tabular}{|c|c|c|c|c|c|c|}
\hline Variables & OR $^{*}$ & $95 \%$ Clt & $P$ value & AOR $\ddagger$ & $95 \% \mathrm{Cl}$ & $P$ value \\
\hline \multicolumn{7}{|l|}{ Maternal conditions/behaviours } \\
\hline \multicolumn{7}{|l|}{ Maternal age at her last birthday (years) } \\
\hline $20-34$ & 1.00 & & & & & \\
\hline $15-19$ & 1.26 & $(0.88$ to 0.80$)$ & 0.212 & & & \\
\hline $35-49$ & 1.33 & (1.03 to 1.72$)$ & 0.027 & & & \\
\hline \multicolumn{7}{|l|}{ Heard about family planning } \\
\hline No & 1.00 & & & & & \\
\hline Yes & 1.27 & (0.96 to 1.69$)$ & 0.100 & & & \\
\hline \multicolumn{7}{|l|}{ Ever had child who later died } \\
\hline No & 1.00 & & & 1.00 & & \\
\hline Yes & 4.06 & $(3.15$ to 5.24$)$ & $<0.001$ & 3.74 & (2.88 to 4.87$)$ & $<0.001$ \\
\hline \multicolumn{7}{|l|}{ Cooking location } \\
\hline Kitchen & 1.00 & & & 1.00 & & \\
\hline Elsewhere in the house & 0.85 & (0.61 to 1.18$)$ & 0.324 & 0.77 & (0.54 to 1.11$)$ & 0.167 \\
\hline Outdoors & 0.80 & (0.61 to 1.04$)$ & 0.100 & 0.70 & (0.53 to 0.94$)$ & 0.018 \\
\hline \multicolumn{7}{|l|}{ Garbage disposal } \\
\hline Burning & 1.00 & & & & & \\
\hline Dumping (throwing outside the house) & 0.98 & $(0.77$ to 1.14$)$ & 0.835 & & & \\
\hline \multicolumn{7}{|c|}{ Mother experienced domestic violence in the past year. } \\
\hline No & 1.00 & & & & & \\
\hline Yes & 0.99 & (0.75 to 1.30$)$ & 0.926 & & & \\
\hline \multicolumn{7}{|l|}{ Neonatal condition } \\
\hline \multicolumn{7}{|l|}{ Neonatal gender } \\
\hline Female & 1.00 & & & & & \\
\hline Male & 0.97 & $(0.78$ to 1.21$)$ & 0.798 & & & \\
\hline \multicolumn{7}{|c|}{ Family have access to improved source of drinking water } \\
\hline Yes & 1.00 & & & 1.00 & & \\
\hline No & 1.76 & (1.10 to 2.81 ) & 0.019 & 1.91 & (1.11 to 3.31 ) & 0.02 \\
\hline \multicolumn{7}{|l|}{$\begin{array}{l}\text { Family have access to improved sanitation } \\
\text { facilities. }\end{array}$} \\
\hline Yes & 1.00 & & & & & \\
\hline No & 1.10 & (0.75 to 1.60$)$ & 0.639 & & & \\
\hline
\end{tabular}

*Unadjusted odds ratio (OR).

†Confidence interval (Cl).

$\ddagger$ Adjusted OR (AOR), and the odds ratio adjusted for all other variables in the table.

including household wealth, the gender and education of the household head, maternal literacy and education, maternal marital status and polygamy status. The entire list of the independent variables with their definitions and the categories can be found in the online supplementary material.

In this analysis, we constructed the household wealth index variable from an inventory of 24 household facilities and assets (such as the material of the dwelling floor, roof and walls; the number of persons per sleeping room; the fuel used for cooking; main source of drinking water; availability of electricity; ownership of radio, television, mobile phone, telephone, refrigerator and watch; ownership of transport devices, such as bicycles, motorcycles/ scooters, animal-drawn carts, cars/trucks, and boats; the source of drinking water and type of sanitation facility; ownership land) using principal components analysis to weight the contribution of the items to the index. ${ }^{23}$ This index was divided into three categories: the bottom one-third of households that were referred to as poor households, the next one-third as the middle-level households and the top one-third as the wealthier households.

At the proximal individual's circumstances/conditions, nine factors were identified and categorised according 
to: (1) maternal conditions/behaviours including maternal age at childbirth, ever had a child who later died, cooking location, garbage disposal, ever heard of family planning and mother's experience of domestic violence; and (2) under-five conditions including the child's gender, access to improved sanitation facilities and access to improved source of drinking water. Unimproved source of water consisted of unprotected wells and springs; unfiltered water from rivers, streams, dams and hafirs; water transported by tankers/carts; and bottled water from unimproved source. Improved source of drinking water consisted of piped water (into dwelling, compound, yard or plot, to neighbour, public tap/standpipe), tube wells/boreholes, protected wells, protected springs, bottled water and water transported by tankers/ carts from improved source.

\section{Ethical approval}

All respondents to the survey provided verbal informed consent; consent for children was obtained through parents, caregivers or guardians when data were originally collected. In 2013, the first author requested for data access from the director of Health Social and Demographic Statistics and from the Ministry of Health of South Sudan, and access was granted to use the data for research. Currently, the data are available from MICS website (http://mics.unicef.org/surveys).

\section{Statistical analysis}

Preliminary analyses were conducted by producing frequency tabulations of all the selected characteristics examined in this study. The preliminary analyses were carried out using STATA/MP V.12 (StataCorp, College Station, TX, USA). ${ }^{24}$ The 'Svy' survey commands were used to allow for adjustments for the cluster sampling design and sampling weights. This was followed by calculating neonatal, infant and under-five mortality rate using a method similar to that described by Rutstein and Rojas. ${ }^{25}$

Univariable and multivariable logistic regression generalised linear latent and mixed models with the logit link and binomial family ${ }^{25}$ that adjusted for cluster and survey weights were used to identify those factors associated with neonatal, infant and under-five mortality. Univariable logistic regression was conducted to determine the unadjusted ORs of the study factors for neonatal, infant and under-five mortality.

In the multivariable logistic regression analysis, a threestage hierarchical model based on a conceptual framework described by Victora $e t a l^{26}$ was performed in this analysis. According to this approach, the effect of distal variables could be assessed without inappropriate adjustment by proximate or intermediate variables that could be mediators of the effects of more distal variables. ${ }^{26}$

In the first-stage model (model 1), all the distal socioeconomic community factors were entered into the model and this was followed by manually executed backward elimination process. Only variables associated with the outcome were retained (model 1 ). In the secondstage model (model 2), the significant factors $(\mathrm{P}<0.05)$ in model 1 were added to socioeconomic (household) level factors and this was followed by a backward elimination procedure but retaining all the significant factors from model 1. In the third and final-stage model (model 3), the individual (maternal and child condition and circumstance) factors were added into model 2 and those variables with $\mathrm{P}<0.05$ in model 3 were retained in the final model including all factors from model 2. The ORs and their 95\% CIs obtained from the adjusted multiple logistics model were used to measure the factors associated with neonatal, infant and under-five mortality.

\section{RESULTS}

There was a total of 785 under-five deaths, with an estimated under-five mortality rate of 101 per 1000 live births, a child mortality rate of 27 per 1000 live births, an infant mortality rate of 74 per 1000 live births, a postneonatal mortality rate of 34 per 1000 live births and neonatal mortality rate of 40 per 1000 live births

Table 1 describes the socioeconomic inequalities between the communities/households alongside under-five mortality rates. This study showed that about three-fourths $(75 \%)$ of the study population resided in rural areas, but there was higher mortality in the urban population (120 per 1000 live births). Nearly all mothers $(90 \%)$ were illiterate and children born to this group of women had a higher rate of under-five mortality (105 per 1000 live births) than those born to literate mothers. Family planning methods were not widely used with only $19 \%$ of women having heard about family planning but surprisingly their under-five children were more likely to die (121 per 1000 live births) compared with those women who never heard about family planning. Our study found a higher underfive mortality rate (180 per 1000 live births) among mothers, who had had a child that later died.

Table 2 shows the unadjusted OR and the adjusted OR (AOR) for factors associated with neonatal mortality. Exposure to indoor air pollution due to use of polluting fuels for cooking was associated with neonatal mortality, with neonates born in households that cooked their food outdoors being significantly protected from neonatal death (AOR $=0.70,95 \%$ confidence interval (CI 0.53 to 0.94), $\mathrm{P}$ 0.018). Higher mortality was found among newborns living in households with unimproved source of drinking water (AOR=1.91, 95\% CI (1.13 to 3.38), P 0.016).

Tables 3 and 4 show the univariate and multivariate analyses for factors associated with infant and under-five mortality. Maternal conditions and circumstances, such as teenage pregnancy, were associated with under-five mortality. For instance, children born to mothers aged 15-19 years were at increased risk of deaths than other children born to older mothers (AOR $=1.85,95 \% \mathrm{CI}$ (1.20 to 2.85), $\mathrm{P}=0.005)$ for infant and $(\mathrm{AOR}=1.77$, 
Table 3 Adjusted and unadjusted ORs for factors associated with infant mortality according to socioeconomic and intermediate factors, analysis of South Sudan Household Survey, $2010(n=8215)$

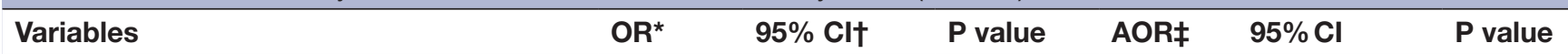

Intermediate determinants

Socioeconomic position

Community factors

Type of cluster

\begin{tabular}{|c|c|c|c|c|c|c|}
\hline Rural & 1.00 & & & 1.00 & & \\
\hline Urban & 1.35 & (1.08 to1.69) & 0.009 & 1.35 & (1.08 to 1.69$)$ & 0.009 \\
\hline \multicolumn{7}{|l|}{ Geographical location (regions) } \\
\hline Greater Upper Nile & 1.00 & & & & & \\
\hline Greater Bahr el Ghazal & 1.09 & (0.85 to 1.41$)$ & 0.505 & & & \\
\hline Greater Equatoria & 1.15 & (0.89 to 1.49$)$ & 0.281 & & & \\
\hline Mean household wealth index in the cluster & 0.97 & $(0.74$ to 1.26$)$ & 0.798 & & & \\
\hline $\begin{array}{l}\text { Proportion of mothers with intermediate } \\
\text { school education in the cluster }\end{array}$ & 1.66 & (0.57 to 4.81$)$ & 0.351 & & & \\
\hline $\begin{array}{l}\text { Mean number of antenatal care visits in the } \\
\text { cluster }\end{array}$ & 0.71 & (0.50 to 1.03$)$ & 0.068 & & & \\
\hline $\begin{array}{l}\text { Percentage of deliveries assisted by trained } \\
\text { birth attendants in the cluster }\end{array}$ & 1.10 & (0.61 to 2.00 ) & 0.755 & & & \\
\hline $\begin{array}{l}\text { Percentage of mothers receiving postnatal } \\
\text { care in the cluster }\end{array}$ & 1.79 & (0.76 to 4.22$)$ & 0.180 & & & \\
\hline \multicolumn{7}{|l|}{ Household factors } \\
\hline \multicolumn{7}{|l|}{ Household wealth index } \\
\hline Wealthier & 1.00 & & & & & \\
\hline Middle & 0.94 & (0.76 to 1.16$)$ & 0.562 & & & \\
\hline Poor & 1.01 & (0.82 to 1.24$)$ & 0.920 & & & \\
\hline \multicolumn{7}{|l|}{ Gender of household head } \\
\hline Male & 1.00 & & & & & \\
\hline Female & 1.00 & (0.83 to 1.19$)$ & 0.967 & & & \\
\hline \multicolumn{7}{|l|}{ Education of the household head } \\
\hline Secondary+ education & 1.00 & & & & & \\
\hline No education/primary education & 1.14 & (0.82 to 1.58$)$ & 0.45 & & & \\
\hline \multicolumn{7}{|l|}{ Maternal education } \\
\hline Intermediate+ education & 1.00 & & & & & \\
\hline Primary education & 0.75 & $(0.48$ to 1.17$)$ & 0.206 & & & \\
\hline No education & 0.80 & (0.53 to 1.21$)$ & 0.298 & & & \\
\hline \multicolumn{7}{|l|}{ Maternal literacy } \\
\hline Able to read & 1.00 & & & 1.00 & & \\
\hline Unable to read & 1.43 & (1.04 to 1.98$)$ & 0.029 & 1.38 & (1.00 to 1.92$)$ & 0.051 \\
\hline \multicolumn{7}{|l|}{ Maternal marital status } \\
\hline Never married (single) & 1.00 & & & 1.00 & & \\
\hline Formerly married & 1.27 & (0.91 to 1.77$)$ & 0.167 & 1.42 & (0.99 to 2.04$)$ & 0.057 \\
\hline Currently married & 1.27 & (0.97 to 1.67$)$ & 0.082 & 1.41 & (1.04 to 1.90$)$ & 0.026 \\
\hline \multicolumn{7}{|l|}{ Polygamy status } \\
\hline Husband had one wife & 1.00 & & & & & \\
\hline Husband had more than one wife & 0.96 & (0.80 to 1.16$)$ & 0.669 & & & \\
\hline Individual's circumstances & & & & & & \\
\hline
\end{tabular}

Continued 


\begin{tabular}{|c|c|c|c|c|c|c|}
\hline Variables & OR $^{\star}$ & $95 \% \mathrm{Cl} \dagger$ & P value & AOR & $95 \% \mathrm{Cl}$ & $P$ value \\
\hline \multicolumn{7}{|l|}{ Maternal conditions/behaviours } \\
\hline \multicolumn{7}{|l|}{ Maternal age at her last birthday (years) } \\
\hline 20-34 & 1.00 & & & 1.00 & & \\
\hline $15-19$ & 1.25 & (0.95 to 1.63$)$ & 0.108 & 1.85 & (1.20 to 2.85$)$ & 0.005 \\
\hline $35-49$ & 1.21 & (0.99 to 1.47$)$ & 0.059 & 1.07 & (0.87 to 1.32$)$ & 0.511 \\
\hline \multicolumn{7}{|l|}{ Heard about family planning } \\
\hline No & 1.00 & & & & & \\
\hline Yes & 1.34 & (1.08 to 1.66$)$ & 0.008 & & & \\
\hline \multicolumn{7}{|l|}{ Ever had child who later died } \\
\hline No & 1.00 & & & 1.00 & & \\
\hline Yes & 3.21 & (2.67 to 3.87$)$ & $<0.001$ & 3.19 & (2.62 to 3.88$)$ & $<0.001$ \\
\hline \multicolumn{7}{|l|}{ Cooking location } \\
\hline Kitchen & 1.00 & & & & & \\
\hline Elsewhere in the house & 0.89 & $(0.70$ to 1.15$)$ & 0.388 & & & \\
\hline Outdoors & 0.90 & $(0.74$ to 1.10$)$ & 0.321 & & & \\
\hline \multicolumn{7}{|l|}{ Garbage disposal } \\
\hline Burning & 1.00 & & & & & \\
\hline Dumping (throwing outside the house) & 0.97 & (0.81 to 1.16$)$ & 0.752 & & & \\
\hline \multicolumn{7}{|c|}{ Mother experienced domestic violence in the past year } \\
\hline No & 1.00 & & & & & \\
\hline Yes & 0.96 & $(0.77$ to 1.18$)$ & 0.670 & & & \\
\hline \multicolumn{7}{|l|}{ Infant condition } \\
\hline \multicolumn{7}{|l|}{ Infant gender } \\
\hline Female & 1.00 & & & 1.00 & & \\
\hline Male & 1.11 & $(0.94$ to 1.31$)$ & 0.241 & 1.22 & (1.01 to 1.47$)$ & 0.035 \\
\hline \multicolumn{7}{|c|}{ Family have access to improved source of drinking water } \\
\hline Yes & 1.00 & & & & & \\
\hline No & 1.36 & (0.99 to 1.87$)$ & 0.055 & & & \\
\hline \multicolumn{7}{|c|}{ Family have access to improved sanitation facilities } \\
\hline Yes & 1.00 & & & & & \\
\hline No & 1.14 & (0.85 to 1.52$)$ & 0.378 & & & \\
\hline
\end{tabular}

*Unadjusted odds ratio (OR).

†Confidence interval $(\mathrm{Cl})$.

$\ddagger$ Adjusted odds ratio (AOR), and the odds ratio adjusted for all other variables in the table.

95\% CI (1.21 to 2.59), P 0.003) for under-five deaths. Other factors significantly associated with infant and under-five deaths included maternal marital status, maternal literacy and gender of the child.

Across all the age ranges (tables 2-4), the results from the multivariate analyses show that children born to mothers who experienced a previous death of a child were at increased risk of neonatal mortality $(\mathrm{AOR}=3.74,95 \% \mathrm{CI}$ (2.88 to 4.87), $\mathrm{P}<0.001)$, infant mortality (AOR=3.19, 95\% CI $(2.62$ to 3.88$), \mathrm{P}<0.001)$ and under-five mortality $(\mathrm{AOR}=3.07,95 \% \mathrm{CI}$ (2.58 to 3.64), $\mathrm{P}<0.001)$. Among the community-level factors living in an urban area was associated with increased risk of neonatal mortality (AOR $=1.37,95 \%$ CI (1.01 to 1.87$)$, $\mathrm{P} 0.045$ ), infant mortality (AOR $=1.35,95 \% \mathrm{CI}$ ( 1.08 to 1.69), $\mathrm{P} \quad 0.009)$ and under-five mortality $(\mathrm{AOR}=1.39$, $95 \%$ CI (1.13 to 1.71$)$, P 0.002).

\section{DISCUSSION}

This study shows the impact of social and material circumstances in which the children are born into, and live with, is significantly associated with increased risk of neonatal, infant and under-five mortality. We found that children of teenage mothers, children living in urban areas, children whose mothers had 
Table 4 Adjusted and unadjusted ORs for factors associated with undermortality according to socioeconomic and intermediate factors, analysis of South Sudan Household Survey, $2010(n=8215)$

\begin{tabular}{lllllll}
\hline Variables & OR $^{*}$ & $95 \% \mathrm{Cl} \dagger$ & P value & AOR & $95 \% \mathrm{Cl}$ & $\mathbf{P}$ value
\end{tabular}

Intermediate determinants

Socioeconomic position

Community factors

Type of cluster

\begin{tabular}{|c|c|c|c|c|c|c|}
\hline Rural & 1.00 & & & 1.00 & & \\
\hline Urban & 1.39 & $(1.13$ to 1.71$)$ & 0.002 & 1.39 & $(1.13$ to 1.71$)$ & 0.002 \\
\hline \multicolumn{7}{|l|}{ Geographical location (regions) } \\
\hline Greater Upper Nile & 1.00 & & & & & \\
\hline Greater Bahr el Ghazal & 1.10 & (0.87 to 1.39$)$ & 0.44 & & & \\
\hline Greater Equatoria & 1.19 & (0.93 to 1.50$)$ & 0.16 & & & \\
\hline Mean household wealth index in the cluster & 0.99 & (0.78 to 1.27$)$ & 0.96 & & & \\
\hline $\begin{array}{l}\text { Proportion of mothers with intermediate } \\
\text { school education in the cluster }\end{array}$ & 1.68 & (0.62 to 4.56$)$ & 0.31 & & & \\
\hline $\begin{array}{l}\text { Mean number of antenatal care visits in the } \\
\text { cluster }\end{array}$ & 0.79 & (0.56 to 1.11$)$ & 0.17 & & & \\
\hline $\begin{array}{l}\text { Percentage of deliveries assisted by trained } \\
\text { birth attendants in the cluster }\end{array}$ & 0.99 & (0.57 to 1.72$)$ & 0.96 & & & \\
\hline $\begin{array}{l}\text { Percentage of mothers receiving postnatal } \\
\text { care in the cluster }\end{array}$ & 1.66 & (0.74 to 3.72$)$ & 0.22 & & & \\
\hline
\end{tabular}

Household factors

Household wealth index

$\begin{array}{llll}\text { Wealthier } & 1.00 & & \\ \text { Middle } & 0.93 & (0.77 \text { to } 1.13) & 0.46 \\ \text { Poor } & 0.96 & (0.79 \text { to } 1.16) & 0.68\end{array}$

Gender of household head

Male $\quad 1.00$

Female $\quad 1.10$

(0.94 to 1.29) 0.25

Education of the household head

Secondary+ education $\quad 1.00$

$\begin{array}{llll}\text { No education/primary education } & 1.20 \quad \text { (0.89 to } 1.62) & 0.24\end{array}$

Maternal education

Intermediate+ education $\quad 1.00$

$\begin{array}{llll}\text { Primary education } & 0.96 & \text { (0.63 to 1.46) } & 0.85\end{array}$

$\begin{array}{llll}\text { No education } & 0.92 & \text { (0.62 to } 1.36) & 0.67\end{array}$

Maternal literacy

$\begin{array}{llll}\text { Able to read } & 1.00 & & \\ \text { Unable to read } & 1.33 & \text { (1.01 to } 1.77) & 0.046\end{array}$

Maternal marital status

$\begin{array}{llll}\text { Never married (single) } & 1.00 & & \\ \text { Formerly married } & 1.16 & \text { (0.86 to } 1.57) & 0.33 \\ \text { Currently married } & 1.24 & \text { (0.97 to } 1.58) & 0.08\end{array}$

Polygamy status

Husband had one wife $\quad 1.00$

$\begin{array}{llll}\text { Husband had more than one wife } & 0.95 & \text { (0.80 to 1.12) } & 0.54\end{array}$

Individual's circumstances

Continued 


\begin{tabular}{|c|c|c|c|c|c|c|}
\hline Variables & OR $^{\star}$ & $95 \% \mathrm{Cl}+$ & $P$ value & AORł & $95 \% \mathrm{Cl}$ & $P$ value \\
\hline \multicolumn{7}{|c|}{ Maternal conditions/behaviours } \\
\hline \multicolumn{7}{|c|}{ Maternal age at her last birthday (years) } \\
\hline $20-34$ & 1.00 & & & 1.00 & & \\
\hline $15-19$ & 1.17 & (0.91 to 1.50$)$ & 0.22 & 1.77 & $2.59)^{(1.2}$ & 0.003 \\
\hline $35-49$ & 1.19 & (1.00 to 1.43$)$ & 0.05 & 1.04 & $1.25)^{(0.8}$ & 0.674 \\
\hline \multicolumn{7}{|c|}{ Heard about family planning } \\
\hline No & 1.00 & & & & & \\
\hline Yes & 1.31 & (1.07 to 1.59$)$ & 0.007 & & & \\
\hline
\end{tabular}

Ever had child who later died

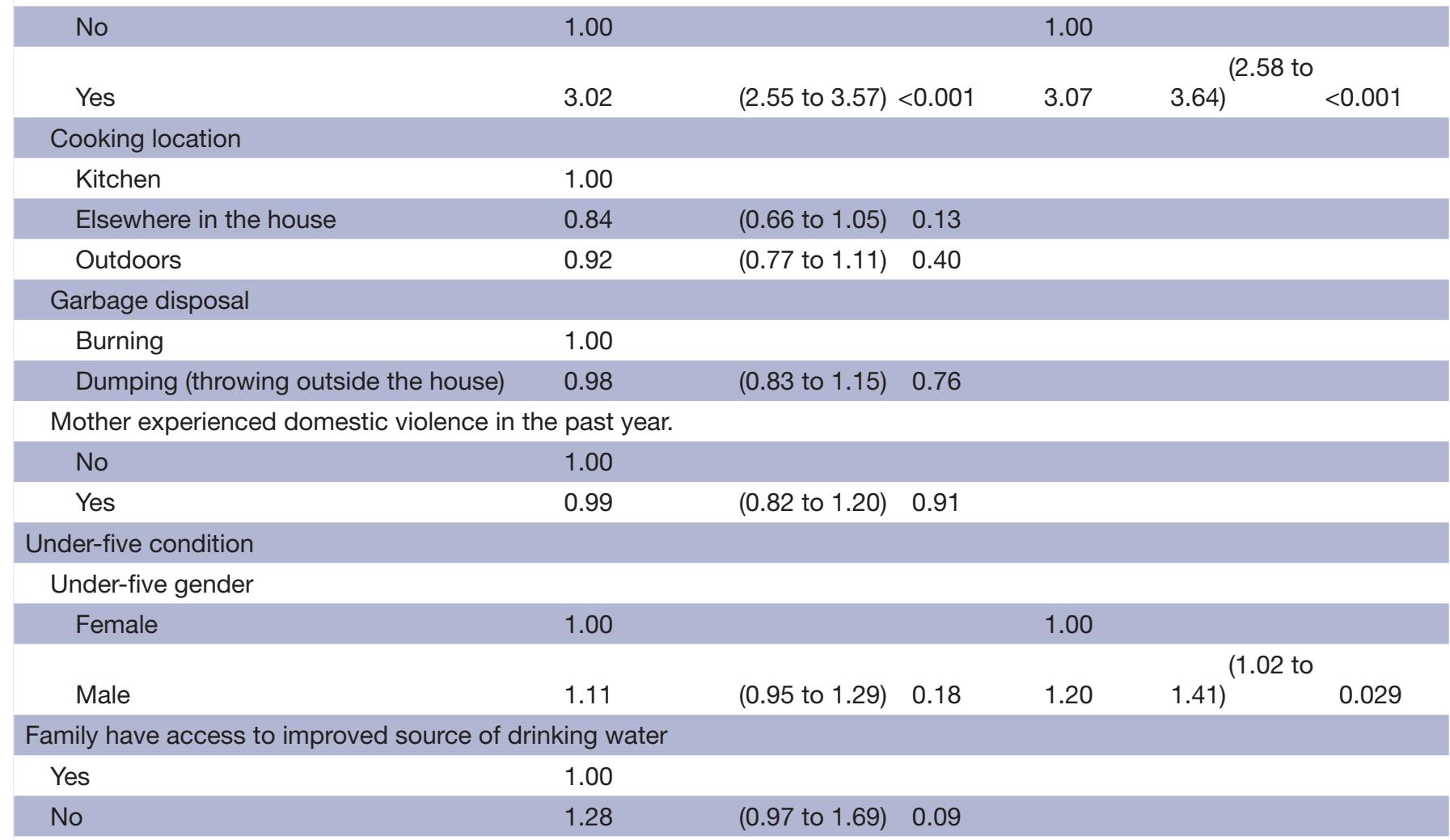

Family have access to improved sanitation facilities

\begin{tabular}{llll} 
Yes & 1.00 & & \\
No & 1.01 & $(0.79$ to 1.30$)$ & 0.93 \\
\hline
\end{tabular}

*Unadjusted odds ratio (OR).

†Confidence interval $(\mathrm{Cl})$.

$\ddagger$ Adjusted odds ratio (AOR), and the odds ratio adjusted for all other variables in the table.

had a prior child death, children born to illiterate mothers and male children all had higher odds of dying before the age of 5 . These results are important as they highlight the need for services in population subgroups, which might not usually be the focus of child survival programmes, for example, urban populations.

Studies from postconflict settings, such as Mozambique and Ethiopia, have found children of urban migrants experience a higher rate of under-five mortality than urban non-migrant children during the period of civil war and conflict. ${ }^{18} 19$ 27-29 This study reported similar findings with under-five children living in urban South Sudan having a higher odds of death compared with those living in the rural areas. This could be due to the in-migration of large numbers of socially and economically disadvantaged groups of South Sudanese returnees, and internally displaced people from North Sudan, after the end of the war for independence searching for work and better social services for their families in Juba. ${ }^{30}$ Under-five children born or growing up in 
such harsh conditions would be more likely to die than children who were better off in rural areas of South Sudan. The Government of South Sudan and non-governmental organization needs to improve and adequately resource services for vulnerable populations but especially in urban areas.

In this study, we found children born to teenage mothers (15-19 years) were at greater risk of death, which is in line with other studies from low/middle-income countries. ${ }^{31}{ }^{32}$ In South Sudan, young girls are exposed to early marriage even as early as 12 years old. ${ }^{33}$ This harmful practice, which is culturally acceptable throughout South Sudan, puts the girl and her offspring at risk of death. Early marriage is harmful because it is a violation of the girl's rights to health, as early pregnancy and childbirth increase her risk of dying or ill health. ${ }^{34}$ Therefore, the government needs to take action to apply the legislation for the legal age of girls in marriage, and take immediate and long-term steps to protect the rights of girls against early or forced marriage to ensure the fulfilment of their human rights. Implementing conditional cash transfer programme targeting poor families to keep their daughters in school and unmarried until secondary school might have a long-term impact on girls' rights for education and reduce teenage marriage.

In this study, children born to mothers with a history of child death had greatly increased the odds of death before the age of 5 years, which is similar to the findings reported in other studies. ${ }^{31}{ }^{35}$ This indicator is found in $28 \%$ of women and it increases the risk of neonatal, infant and under-five death substantially. An analysis of the characteristics of these women and their households suggests that children born to these mothers face a higher risk of death possibly due to household poverty, having siblings less than 2 years and a father with more than one wife. Policies to alleviate the socioeconomic disparity within the communities, and to address the factors associated with poor living conditions are essential, such as provision of a social safety net and welfare support for disadvantaged households.

In this study, we found under-five male children having $20 \%$ higher odds of dying than female children, and similar findings have been reported in other studies. ${ }^{16}{ }^{36-38}$ Several studies indicate that under-five male children are at higher risk of death as a result of biological factors, such as immunodeficiency due to late maturity and congenital malformations of urogenital system, ${ }^{39} 40$ which make them more vulnerable to infectious diseases. Reducing the risks for under-five mortality for both female and male children will be a challenge in South Sudan since access to newborn, infant and child health services is relatively low. The Government of South Sudan will need to address the access problem at both the community and individual levels, and deal with the lack of qualified staff and healthcare facilities in order to meet the needs of under-five children.

In this study, exposure to indoor air pollution and use of unimproved source of drinking water were associated with increased risk of neonatal mortality, which was consistent with previous studies from low/ middle-income countries. ${ }^{41-44}$ In South Sudan, the majority of households with newborn children lack access to sanitary facilities $(89 \%)$, have poor personal hygiene practices, lack access to improved sources of drinking water $(90 \%)$ and use polluting fuels for cooking $(99 \%)$. Under-five children born and growing up in such an unhygienic environment are at increased risk for childhood diseases such as diarrhoea and pneumonia. Therefore, implementing a cost-effective public health-related intervention to improve household environmental conditions, such as access to improved source of drinking water and sanitation facility, might have a positive impact on reducing environmental health and thus childhood mortality.

Previous studies indicate that maternal education can influence the survival of under-five children. ${ }^{45}{ }^{46}$ Our study reported similar findings with infants born to illiterate mothers being more likely to die than those born to literate mothers. Therefore, long-term investments in South Sudan in child education for both girls and boys are essential since educational attainment is associated with improved socioeconomic status in adulthood, increased use of maternal and child healthcare services, and reduced teenage marriage and pregnancy.

The results from this analysis might not reflect the current situation of under-five children and their needs for access to lifesaving interventions because of the continuation of armed violence that broke out in multiple cities of South Sudan in December 2013. ${ }^{47}$ It is estimated that since December 2013, nearly 3 million people in South Sudan have been displaced, and of these 1.1 million people sought refuge in neighbouring countries with children comprising $70 \%$ of refugees. ${ }^{48}$ Also about $31 \%$ of the population are food insecure and 276343 children are likely to be affected by severe acute malnutrition. ${ }^{49} 50$ Women and children are at immediate risks of violence, sexual abuse, exploitation and life-threatening diseases. Further complicating the situation is a deterioration of the economic situation, renewed conflict since July 2016 and increased insecurity throughout the country. ${ }^{50}$ Nonetheless, our findings remain important for future assessment of the cost-effective lifesaving intervention for under-five children once the conflict ceases in South Sudan.

This is the first analysis that reports the determinants of under-five mortality in South Sudan. The study strengths include a representative national sample of women and their children, a high response rate $(81 \%)$ and appropriate adjustments in the analysis for the sampling design. We were able to identify the risk factors that could help with targeting programmes for under-five children in South Sudan. Also data on birth history were collected for 5 years prior to the survey to minimise potential maternal recall bias. The limitations in our study include the use of cross-sectional survey data that restricts the interpretation of the causality of factors associated with under-five mortality. Nonetheless, several of the key factors we examined were present 
before the child mortality outcomes, for example, maternal age, and maternal history of a child death, strengthening the case for them having a causal role in child deaths in South Sudan. The potential factors associated with under-five deaths examined in this analysis were restricted to those factors available in SSHHSII data. The survey data used relied on a mother's ability to remember details about her birth history.

\section{CONCLUSIONS}

This study highlights the role of social and material circumstances in which the children are born into, and live with, and their association with higher risk of neonatal, infant and under-five mortality. Implementing programmes targeting the structural and intermediate determinates of health inequality is essential in South Sudan but remains a challenge, while violence continues in South Sudan. Government and policymakers should develop regional and local policies to tackle the upstream causes of socioeconomic health inequalities. Improving and adequately resourcing services, as well as ensuring equitable service delivery to all disadvantaged populations of women and children in both urban and rural areas should be a priority. The Government of South Sudan and international agencies need to implement programmes to alleviate poverty among poor households in order to increase the demand for education and health services among the poor. For instance, implementing a cash transfer programme targeting poor families to keep their daughters in school and unmarried throughout their secondary education is essential. In order to improve under-five survival, it is also essential to develop interventions targeting poor households and mothers with a history of child death. Incentive programmes are also needed to encourage disadvantaged women to attend health services during pregnancy, delivery and when their child is born to improve health outcomes for themselves and for their children.

Acknowledgements We thank Dr Richard Lino Lako, Ministry of Health of South Sudan, for providing access to SSHHSII.

Contributors NSM and MJD contributed to the study design. NSM, KEA and MJD performed the analysis and NSM prepared the manuscript. Revision of the manuscript and data analysis advice were provided by MJD, ABZ, KEA and EYD. All authors read and approved the final manuscript.

Funding This research received no specific grant from any funding agency in the public, commercial or not-for-profit sectors.

Disclaimer The views expressed in the submitted article are those of the authors and not an official position of the institution or funder.

Competing interests None declared.

Patient consent Guardian consent obtained.

Ethics approval The Ethics Committee of the Ministry of Health, Government of South Sudan, reviewed and approved the survey design of the SSHHSII.

Provenance and peer review Not commissioned; externally peer reviewed.

Data sharing statement All the datasets that were used are publicly available on MICS website. The code for dataset analysis is available from the corresponding author on request.

Open Access This is an Open Access article distributed in accordance with the Creative Commons Attribution Non Commercial (CC BY-NC 4.0) license, which permits others to distribute, remix, adapt, build upon this work non-commercially, and license their derivative works on different terms, provided the original work is properly cited and the use is non-commercial. See: http://creativecommons.org/ licenses/by-nc/4.0/

Author note This analysis is part of the first author's thesis to fulfil the requirement for $\mathrm{PhD}$ in International Public Health at the University of Sydney.

(c) Article author(s) (or their employer(s) unless otherwise stated in the text of the article) 2018. All rights reserved. No commercial use is permitted unless otherwise expressly granted.

\section{REFERENCES}

1. United Nations. The Sustainable Development Goals Report 2016. New York, 2016

2. United Nations. The Millennium Development Goals Report 2015: New York, 2015.

3. UNICEF, World Health Orgnization, World Bank Group. Levels \& Trends in Child Mortality Report 2015: Estimates Developed by the UN Inter-agency Group for Child Mortality Estimation. New York, USA: United Nations Children's Fund, 2015.

4. UNICEF. Committing to Child Survival: A Promise Renewed Progress Report. New York, USA: United Nations Children's Fund, 2015.

5. Grusovin K, Makome A, Nayak B, et al. Machel Study 10-Year Strategic Review - Children and Conflict in a Changing World. New York: United Nations Children's Fund, 2009:224.

6. WHO. World health statistics 2016: monitoring health for the SDGs, sustainable development goals. Switzerland, 2016.

7. Taylor S. Research Report: Beyond the Health Governance Gap: Maternal, newborn and child health in South Sudan. Worl vision, UK 2012.

8. Wakabi W. South Sudan faces grim health and humanitarian situation. Lancet 2011;377:2167-8.

9. National Bureau of Statistics. National Baseline Household Survey 2009: Report for South Sudan. Juba, South Sudan, 2012. https:// reliefweb.int/sites/reliefweb.int/files/resources/NBHS\%20Final\% 20website.pdf.

10. Taylor S. Beyond the Health Governance Gap Maternal, newborn and child health in South Sudan. London, SWIV: World Vision UKLondon office, 2012.

11. Government of South Sudan (GoSS), Ministry of Health (MoH) UNFPA. Southern Sudan Maternal, Neonatal and Reproductive Health Strategy: Action Plan 2008-11. Juba, South Sudan, 2007.

12. Ministry of Health, National Bureau of Statistics, UNICEF. South Sudan Household Survey 2010, Final Report. Juba, South Sudan, 2013.

13. Mugo N, Zwi AB, Botfield JR, et al. Maternal and Child Health in South Sudan: Priorities for the Post-2015 Agenda. SAGE Open 2015;5:1-14

14. Solar O, Irwin A. A Conceptual Framework for Action on the Social Determinants of Health. Social Determinants of Health Discussion Paper 2 (Policy and Practice). Geneva, 2010.

15. Commission on Social Determinants of Health (CSDH). Closing the gap in a generation: health equity through action on the social determinants of health. Final Report of the Commission on Social Determinants of Health Geneva. Geneva, 2008.

16. Khadka KB, Lieberman LS, Giedraitis V, et al. The socio-economic determinants of infant mortality in Nepal: analysis of Nepal Demographic Health Survey, 2011. BMC Pediatr 2015;15:152.

17. Houweling TA, Kunst AE. Socio-economic inequalities in childhood mortality in low- and middle-income countries: a review of the international evidence. Br Med Bull 2010;93:7-26.

18. Macassa G, Ghilagaber G, Bernhardt E, et al. Trends in infant and child mortality in Mozambique during and after a period of conflict. Public Health 2003;117:221-7.

19. Avogo WA, Agadjanian V. Forced migration and child health and mortality in Angola. Soc Sci Med 2010;70:53-60.

20. Arnaldo C. Armed conflict and demographic outcomes in Mozambique and Rwanda: What can censuses tell us? Continuity and Change in Sub-Saharan African Demography 2014:284-302.

21. Ministry of Health, National Bureau of Statistics. The Republic of South Sudan: The Sudan Household Health Survey 2010. Juba, South Sudan, 2013. http://www.ssnbss.org/sites/default/files/ 201608/Sudan_Household_Health Survey Report 2010.pdf

22. Keith LG, Oleszczuk JJ, Keith DM. Multiple gestation: reflections on epidemiology, causes, and consequences. Int J Fertil Womens Med 2000;45:206-14.

23. Filmer D, Pritchett LH. Estimating wealth effects without expenditure data-or tears: an application to educational enrollments in states of India. Demography 2001;38:115-32. 
24. StataCorp. Stata: Release 13. Statistical Software. College Station, TX: StataCorp LP2013.

25. Rutstein S, Rojas G. Guide to Demographic and Health Survey (DHS). Calverton, MD: ORC Macro, 2006.

26. Victora CG, Huttly SR, Fuchs SC, et al. The role of conceptual frameworks in epidemiological analysis: a hierarchical approach. Int J Epidemiol 1997;26:224-7.

27. Kiros GE, Hogan DP. War, famine and excess child mortality in Africa: the role of parental education. Int $J$ Epidemiol 2001:30:447-55.

28. Reeder BW, Reeder MR, Violence P. Interstate Rivalry, and the Diffusion of Public Health Crises. Social Science Quarterly 2014;95:1101-20.

29. Brockerhoff M. Rural-to-urban migration and child survival in Senegal. Demography 1990;27:601-16.

30. Ministry of Health. Reproductive Health/Family Planning Service Provision for Returning Populations to South Sudan: Assessment Findings \& Recommendations. Washington, D.C, 2006

31. Abir T, Agho KE, Page AN, et al. Risk factors for under-5 mortality: evidence from Bangladesh Demographic and Health Survey, 20042011. BMJ Open 2015;5:e006722.

32. Arokiasamy P, Gautam A. Neonatal mortality in the empowered action group states of India: trends and determinants. J Biosoc Sci 2008;40:183-201.

33. Stern O. This is how marriage happens sometimes: women and marriage in South Sudan. In: Bubenzer F, Stern O, eds. Hope, Pain \& Patience: The Lives of Women in South Sudan. South Africa: FaneleJacana Media, 2011:1-23.

34. Watch HR. "This Old Man Can Feed Us, You Will Marry Him" Child and Forced Marriage in South Sudan. United States of America, 2013.

35. Sear R, Steele F, McGregor IA, et al. The effects of kin on child mortality in rural Gambia. Demography 2002;39:43-63.

36. Nisar YB, Dibley MJ. Determinants of neonatal mortality in Pakistan: secondary analysis of Pakistan Demographic and Health Survey 2006-07. BMC Public Health 2014;14:663.

37. Hobcraft JN, McDonald JW, Rutstein SO. Demographic Determinants of Infant and Early Child Mortality: A Comparative Analysis. Popul Stud 1985;39:363-85.
38. Hong R, Mishra V, Michael J. Economic disparity and child survival in Cambodia. Asia Pac J Public Health 2007:19:37-44.

39. Green MS. The male predominance in the incidence of infectious diseases in children: a postulated explanation for disparities in the literature. Int J Epidemiol 1992;21:381-6.

40. Alonso V, Fuster V, Luna F. Causes of neonatal mortality in Spain (1975-98): influence of sex, rural-urban residence and age at death. J Biosoc Sci 2006;38:537-51.

41. Naz S, Page A, Agho KE. Household air pollution and under-five mortality in India (1992-2006). Environ Health 2016;15:54.

42. Rehfuess EA, Tzala L, Best N, et al. Solid fuel use and cooking practices as a major risk factor for ALRI mortality among African children. J Epidemiol Community Health 2009;63:887-92.

43. Bruce N, Perez-Padilla R, Albalak R. Indoor air pollution in developing countries: a major environmental and public health challenge. Bull World Health Organ 2000;78:1078-92.

44. Ezeh OK, Agho KE, Dibley MJ, et al. The impact of water and sanitation on childhood mortality in Nigeria: evidence from demographic and health surveys, 2003-2013. Int J Environ Res Public Health 2014;11:9256-72.

45. Vallières F, Hansen A, McAuliffe E, et al. Head of household education level as a factor influencing whether delivery takes place in the presence of a skilled birth attendant in Busia, Uganda: a cross-sectional household study. BMC Pregnancy Childbirth 2013;13:48

46. Kanmiki EW, Bawah AA, Agorinya I, et al. Socio-economic and demographic determinants of under-five mortality in rural northern Ghana. BMC Int Health Hum Rights 2014;14:24.

47. Word Heath Organization. Puplic health risk assessment and interventions-conflict and humantrain crises in South Sudan. Geneva Switzerland 2014.

48. United Nations Office for the Coordination of Humanitarian Affairs (OCHA). 'Humanitarian Bulletin South Sudan', issue 18, OCHA, 2016

49. Food and Agricultural Organization of the United Nations. Global Early Warning - Early Action Report on Food Security and Agriculture, October, 2016.

50. UNICEF. Humanitarian Action for Children. South Sudan, 2017. https://www.unicef.org/appeals/files/2017_South-Sudan_HAC(1).pdf (accessed 16 Oct 2017). 